\title{
Skill development among rural women on reuse of textiles
}

\section{Jyotika Choudhary and Rupal Babel}

Received: 08.07.2019; Revised: 06.11.2019; Accepted: 20.11.2019

See end of the paper for authors' affiliations Jyotika Choudhary Department of Textiles and Apparel Designing, College of Community and Applied Sciences, Maharana Pratap University of Agriculture and Technology, Udaipur (Rajasthan) India

Email : jyotikachoudhary1996@ gmail.com
ABSTRACT : Skill and knowledge are the motivating factors of the economic growth and community development of any country. The poverty and unemployment problems will be solved through vocational skill training. The present investigation was undertaken to study the utilization of used textiles. The study was conducted on rural women in the village of Savina Kheda, Udaipur district of Rajasthan. The objectives of the present investigation were to study the existing knowledge and identify the training needs of rural women in the area of the utilization of used textiles. Impact of training was assessed through developed products. This study enables them to develop their entrepreneurial skills and reduce the landfills in rural area which is helpful in both economical growth of rural women and a step towards nature friendliness as landfills can be reduced.

KEY WORDS: Skill development, Rural women, Training, Utilization

- HOW TO CITE THIS PAPER : Choudhary, Jyotika and Babel, Rupal (2019). Skill development among rural women on reuse of textiles. Asian J. Home Sci., 14 (2) : 421-424, DOI: 10.15740/HAS/AJHS/14.2/ 421-424. Copyright@ 2019: Hind Agri-Horticultural Society. 